Pacific Journal of Mathematic 


\title{
SEQUENCES OF CONTRACTIVE MAPS AND FIXED POINTS
}

\author{
R. B. Fraser, JR., AND S. B. NADler, JR. \\ Dedicated to Apollo XI
}

Let $\left(X, \rho_{0}\right)$ be a metric space and, for each $n=0,1,2, \cdots$, let $f_{n}: X \rightarrow X$ be a function with fixed point $a_{n}$. Assume that each function $f_{n}$ is contractive with respect to a (possibly) different metric $\rho_{n}$, where each $\rho_{n}$ is equivalent to $\rho_{0}$. This paper is concerned with the behavior of the sequence $\left\{a_{n}\right\}_{n=1}^{\infty}$ when $\left\{f_{n}\right\}_{n=1}^{\infty}$ converges pointwise to $f_{0}$.

In $\S 1$ an example of a compact space $\left(X, \rho_{0}\right)$ is given such that, though $\left\{\rho_{n}\right\}_{n=1}^{\infty}$ converges pointwise to $\rho_{0},\left\{a_{n}\right\}_{n=1}^{\infty}$ converges, and $f_{n}$ has $\rho_{n}$-Lipschitz constant $1 / 2,\left\{a_{n}\right\}_{n=1}^{\infty}$ does not converge to $a_{0}$. In $\S 2$ some theorems are proved assuming uniform convergence of $\left\{\rho_{n}\right\}_{n=1}^{\infty}$ to $\rho_{0}$. The example in $\S 1$ shows that none of the results in $\S 2$ remains valid if uniform convergence of the metrics is replaced by pointwise convergence. In $\$ 3$ a fixed point theorem for compact nonempty setvalued contractive mappings is proved and it is shown that the analogous statement for closed and bounded nonempty set-valued contractive mappings is false. It is then indicated how the results of $\S 2$ can be extended to compact nonempty set-valued contractive mappings.

Let $(X, \rho)$ be a metric space. A function $f: X \rightarrow X$ is said to be a $\rho$-contraction if and only if there exists $\lambda, 0 \leqq \lambda<1$, such that $\rho(f(x), f(y)) \leqq \lambda \rho(x, y)$ for all $x, y \in X(\lambda$ is called a $\rho$-Lipschitz constant for $f$ ). A function $f: X \rightarrow X$ is said to be $\rho$-contractive if and only if $\rho(f(x), f(y))<\rho(x, y)$ for all $x, y \in X, x \neq y$.

The following theorem was proved in [4].

TheOREM A. Let $(X, \rho)$ be a locally compact metric space, let $f_{n}: X \rightarrow X$ be a $\rho$-contraction with fixed point $a_{n}$ for each $n=1,2, \cdots$, and let $f_{0}: X \rightarrow X$ be a $\rho$-contraction with fixed point $a_{0}$. If the sequence $\left\{f_{n}\right\}_{n=1}^{\infty}$ converges pointwise to $f_{0}$, then the sequence $\left\{a_{n}\right\}_{n=1}^{\infty}$ converges to $a_{0}$.

In [5] it was shown that closed and bounded nonempty setvalued contraction mappings defined on a complete space have fixed points. Theorem A and other results in [4] were generalized to compact nonempty set-valued contractions.

Throughout this paper two metrics, $d_{1}$ and $d_{2}$, for the same set 
$X$ will be called equivalent if and only if the identity mapping from $\left(X, d_{1}\right)$ to $\left(X, d_{2}\right)$ is a homeomorphism.

1. The example. Let $X=\left\{\left(2^{-i}, 2^{-j}\right) \mid i, j=0,1,2, \cdots, \infty\right\}$ with the convention that $2^{-\infty}=0$. Let $x, y \in X$ and assume $x=\left(2^{-k}, 2^{-l}\right)$ and $y=\left(2^{-m}, 2^{-p}\right)$. For each integer $n>0$ let

$$
\rho_{n}(x, y)=\rho_{n}(y, x)= \begin{cases}\left|2^{-k}-2^{-m}\right| & \text { if } l=p=n, \\ 2-2^{-k}+2^{-p}, & \text { if } l=n, p \neq n \\ 4, & \text { and } m=0, \\ & \text { if } l=n, p \neq n \\ & \text { and } m \neq 0, \\ \left|2^{-l}-2^{-p}\right|, & \text { if } l \neq n, p \neq n \\ 4 & \text { and } m=k=0, \\ & \text { if } l \neq n, p \neq n, \\ \left|2^{-k}-2^{-m}\right|+\left|2^{-l}-2^{-p}\right|, & \text { if } l \neq n, p \neq n, \\ & m \neq 0 \text { and } k \neq 0 ;\end{cases}
$$

and let

$$
\rho_{0}(x, y)=\rho_{0}(y, x)= \begin{cases}4, & \text { if } k=0 \text { and } m \neq 0, \\ \left|2^{-k}-2^{-m}\right|+\left|2^{-l}-2^{-p}\right|, & \text { if } k \neq 0 \text { and } m \neq 0, \\ \left|2^{-l}-2^{-p}\right| & , \text { if } k=0 \text { and } m=0 .\end{cases}
$$

It is easy to verify that, for each integer $n \geqq 0, \rho_{n}$ is a metric on $X$ which is equivalent to the metric on $X$ inherited from the plane. Furthermore, $\left\{\rho_{n}\right\}_{n=1}^{\infty}$ converges pointwise to $\rho_{0}$.

For each integer $n>0$ let $f_{n}: X \rightarrow X$ be given by

$$
f_{n}\left(2^{-i}, 2^{-j}\right)= \begin{cases}\left(2^{-(i+1)}, 2^{-n}\right), & \text { if } j=n, \\ \left(1,2^{-n}\right) & , \text { if } j \neq n \text { and } i=0, \\ (1,0) & , \text { if } j \neq n \text { and } i \neq 0 .\end{cases}
$$

Define $f_{0}: X \rightarrow X$ by $f_{0}(x)=(1,0)$ for all $x \in X$. It is easy to prove that

(1) for each $n \geqq 0, f_{n}$ is a $\rho_{n}$-contraction mapping with $\rho_{n^{-}}$ Lipschitz constant equal to $1 / 2$;

(2) the sequence $\left\{f_{n}\right\}_{n=1}^{\infty}$ converges pointwise to $f_{0}$;

(3) the mapping $f_{n}$ has fixed point

$$
a_{n}= \begin{cases}\left(0,2^{-n}\right), & n>0, \\ (1,0), & n=0 ;\end{cases}
$$

(4) the sequence $\left\{a_{n}\right\}_{n=1}^{\infty}$ of fixed points converges to $(0,0)$ and not to the fixed point $(1,0)$ of the limit function $f_{0}$. 
2. Theorems for single-valued mappings. The following lemma will be useful.

Lemma 1. Let $\left(X, \rho_{0}\right)$ be a metric space and $K$ a compact subset of $X$. Let $\left\{\rho_{n}\right\}_{n=1}^{\infty}$ be a sequence of metrics converging uniformly to $\rho_{0}$ such that each $\rho_{n}$ is equivalent to $\rho_{0}$, and let $\left\{f_{n}\right\}_{n=1}^{\infty}$ be a sequence of $\rho_{n}$-contractive mappings converging pointwise on $X$ to a function $f_{0}$. Then the sequence $\left\{f_{n}\right\}_{n=1}^{\infty}$ converges $\left(\rho_{0}-\right)$ uniformly on $K$ to $f_{0}$.

Proof. Let $\eta>0$ and choose $\delta=\eta / 3$. Let $N$ be a natural number such that if $n>N$ then $\left|\rho_{n}(x, y)-\rho_{0}(x, y)\right|<\delta$ for all $x, y \in X$. If $n>N$ and $x, y \in X$ such that $\rho_{0}(x, y)<\delta$, then

$$
\begin{aligned}
\rho_{0}\left(f_{n}(x), f_{n}(y)\right) & <\delta+\rho_{n}\left(f_{n}(x), f_{n}(y)\right)<\delta+\rho_{n}(x, y) \\
& <\delta+\delta+\rho_{0}(x, y)<3 \delta=\eta .
\end{aligned}
$$

Hence if $x, y \in X$ and $\rho_{0}(x, y)<\delta$, then $\rho_{0}\left(f_{n}(x), f_{n}(y)\right)<\eta$ for all $n>N$. Since $f_{1}, f_{2}, \cdots, f_{N}$ are each $\left(\rho_{0}-\right)$ uniformly continuous on $K$, the sequence $\left\{f_{n}\right\}_{n=1}^{\infty}$ is $\left(\rho_{0}-\right)$ equicontinuous on $K$. Therefore, since $K$ is compact and $\left\{f_{n}\right\}_{n=1}^{\infty}$ converges pointwise to $f_{0}$, it follows that $\left\{f_{n}\right\}_{n=1}^{\infty}$ converges $\left(\rho_{0}-\right)$ uniformly on $K$ to $f_{0}$. This completes the proof of the lemma.

REMARK. Under the conditions of Lemma 1, without assuming $\rho_{n}$ is equivalent to $\rho_{0}$, it is not difficult to prove that $f_{0}$ is $\rho_{0}$-nonexpansive. Let $x, y \in X$ and let $\varepsilon>0$. Choose $N$ such that if $n \geqq N$ then $\rho_{n}$ is uniformly within $\varepsilon / 4$ of $\rho_{0}, \rho_{0}\left(f_{n}(x), f_{0}(x)\right)<\varepsilon / 4$, and $\rho_{0}\left(f_{n}(y)\right.$, $\left.f_{0}(y)\right)<\varepsilon / 4$. Then, if $n \geqq N$,

$$
\begin{aligned}
& \rho_{0}\left(f_{0}(x), f_{0}(y)\right) \leqq \rho_{0}\left(f_{0}(x), f_{n}(x)\right)+\rho_{0}\left(f_{n}(x), f_{n}(y)\right) \\
& +\rho_{0}\left(f_{n}(y), f_{0}(y)\right)<\varepsilon / 4+\rho_{n}\left(f_{n}(x), f_{n}(y)\right)+\varepsilon / 4+\varepsilon / 4 \\
& <\rho_{n}(x, y)+3 \varepsilon / 4<\rho_{0}(x, y)+\varepsilon .
\end{aligned}
$$

Since $\varepsilon$ was arbitrary, $f_{0}$ is $\rho_{0}$-nonexpansive.

The following theorem is a generalization of Theorem $\mathrm{A}$, even in the case when each $\rho_{n}=\rho_{0}$, because each $f_{n}$ for $n=0,1,2, \cdots$ is assumed to be only contractive.

THEOREM 1. Let $\left(X, \rho_{0}\right)$ be a locally compact metric space and assume $\left\{\rho_{n}\right\}_{n=1}^{\infty}$ and $\left\{f_{n}\right\}_{n=0}^{\infty}$ satisfy the hypotheses of Lemma 1. If $f_{0}$ is $\rho_{0}$-contractive and $f_{n}$ has fixed point $a_{n}$ for each $n=0,1,2, \cdots$. then the sequence $\left\{a_{n}\right\}_{n=1}^{\infty}$ converges to $a_{0}$. 
Proof. Let $\varepsilon>0$ be chosen such that $K\left(a_{0}, \varepsilon\right)=\left\{x \in X \mid \rho_{0}\left(a_{0}, x\right) \leqq \varepsilon\right\}$ is a compact subset of $X$. Since Lemma 1 applies, $\left\{f_{n}\right\}_{n=1}^{\infty}$ converges uniformly on $K\left(a_{0}, \varepsilon\right)$ to $f_{0}$. Choose a natural number $N$ such that if $n \geqq N$ and $x \in K\left(a_{0}, \varepsilon\right)$, then

$$
\rho_{0}\left(f_{n}(x), f_{0}(x)\right)<\mu=\varepsilon-\sup \left\{\rho_{0}\left(f_{0}(z), a_{0}\right) \mid z \in K\left(a_{0}, \varepsilon\right)\right\}
$$

(clearly $\mu>0$ by the $\rho_{0}$-contractiveness of $f_{0}$ and the compactness of $\left.K\left(a_{0}, \varepsilon\right)\right)$. Then, if $n \geqq N$ and $x \in K\left(a_{0}, \varepsilon\right)$,

$$
\begin{aligned}
\rho_{0}\left(f_{n}(x), a_{0}\right) & \leqq \rho_{0}\left(f_{n}(x), f_{0}(x)\right)+\rho_{0}\left(f_{0}(x), a_{0}\right) \\
& <\mu+\rho_{0}\left(f_{0}(x), a_{0}\right) \leqq \mu+(\varepsilon-\mu)=\varepsilon .
\end{aligned}
$$

Thus, for $n \geqq N, f_{n}$ maps $K\left(a_{0}, \varepsilon\right)$ into itself. Letting $g_{n}$ be the restriction of $f_{n}$ to $K\left(a_{0}, \varepsilon\right)$ for each $n \geqq N$, we see that $g_{n}$ is a $\rho_{n}$ contractive mapping of the $\left(\rho_{n}-\right)$ compact metric space $K\left(a_{0}, \varepsilon\right)$ into itself. Therefore, $g_{n}$ has a fixed point in $K\left(a_{0}, \varepsilon\right)$ for each $n \geqq N$ [1] which must, from the definition of $g_{n}$ and the fact that $f_{n}$ has only one fixed point, be $a_{n}$. Hence, $a_{n} \in K\left(a_{0}, \varepsilon\right)$ for each $n \geqq N$. It follows that the sequence $\left\{a_{n}\right\}_{n=1}^{\infty}$ converges to $a_{0}$.

Theorem 2. Let $\left(X, \rho_{0}\right)$ be a metric space and assume $\left\{\rho_{n}\right\}_{n=1}^{\infty}$ and $\left\{f_{n}\right\}_{n=0}^{\infty}$ satisfy the hypotheses of Lemma 1. If $f_{n}$ has fixed point $a_{n}$ for each $n=1,2, \cdots$ and some subsequence of $\left\{a_{n}\right\}_{n=1}^{\infty}$ converges to a point $x_{0} \in X$, then $x_{0}$ is a fixed point of $f_{0}$. In particular, if $f_{0}$ is $\rho_{0}$-contractive with (unique) fixed point $a_{0}$, then $x_{0}=a_{0}$.

Proof. Let $\left\{a_{n_{i}}\right\}_{i=1}^{\infty}$ be a subsequence of $\left\{a_{n}\right\}_{n=1}^{\infty}$ such that $\left\{a_{n_{i}}\right\}_{i=1}^{\infty}$ converges to a point $x_{0} \in X$. Applying Lemma 1 to $K=\left\{x_{0}, a_{n_{1}}, a_{n_{2}}, \cdots\right\}$, we see that $\left\{f_{n_{i}}\right\}_{i=1}^{\infty}$ converges uniformly on $K$ to $f_{0}$. Hence, $\left\{f_{n_{i}}\left(a_{n_{i}}\right)\right\}_{i=1}^{\infty}$ converges to $f_{0}\left(x_{0}\right)$. But, since $f_{n_{i}}\left(a_{n_{i}}\right)=a_{n_{i}}$ for each $i=1,2, \cdots$ and since $\left\{a_{n_{i}}\right\}_{i=1}^{\infty}$ converges to $x_{0}$, this proves that $f_{0}\left(x_{0}\right)=x_{0}$.

Theorem 3. Let $\left(X, \rho_{0}\right)$ be a metric space, let $\left\{\rho_{n}\right\}_{n=1}^{\infty}$ be a sequence of metrics converging uniformly to $\rho_{0}$, and let $\left\{f_{n}\right\}_{n=1}^{\infty}$, each $f_{n}$ having fixed point $a_{n}$, be a sequence of $\rho_{n}$-contractions converging $\rho_{0}$-pointwise on $X$ to a function $f_{0}$ with fixed point $a_{0}$. If there exists $\beta<1$ such that, for each $n=1,2, \cdots, \beta$ is a $\rho_{n}$-Lipschitz constant for $f_{n}$, then the sequence $\left\{a_{n}\right\}_{n=1}^{\infty}$ converges to $a_{0}$.

Proof. Let $\varepsilon>0$. Choose a natural number $N$ such that if $n \geqq N$, then

$$
\left|\rho_{n}(x, y)-\rho_{0}(x, y)\right|<\frac{1-\beta}{2+\beta} \cdot \varepsilon
$$


for all $x, y \in X$ and

$$
\rho_{0}\left(f_{n}\left(a_{0}\right), a_{0}\right)<\frac{1-\beta}{2+\beta} \cdot \varepsilon .
$$

Then, for $n \geqq N$,

$$
\begin{gathered}
\rho_{0}\left(a_{n}, a_{0}\right) \leqq \rho_{0}\left(f_{n}\left(a_{n}\right), f_{n}\left(a_{0}\right)\right)+\rho_{0}\left(f_{n}\left(a_{0}\right), f_{0}\left(a_{0}\right)\right)<\rho_{n}\left(f_{n}\left(a_{n}\right), f_{n}\left(a_{0}\right)\right) \\
+\frac{2(1-\beta)}{2+\beta} \cdot \varepsilon \leqq \beta \rho_{n}\left(a_{n}, a_{0}\right)+\frac{2(1-\beta)}{2+\beta} \cdot \varepsilon<\beta \rho_{0}\left(a_{n}, a_{0}\right) \\
+\frac{\beta(1-\beta)}{2+\beta} \cdot \varepsilon+\frac{2(1-\beta)}{2+\beta} \cdot \varepsilon=\beta \rho_{0}\left(a_{n}, a_{0}\right)+(1-\beta) \cdot \varepsilon
\end{gathered}
$$

Hence, if $n \geqq N, \rho_{0}\left(a_{n}, a_{0}\right)<\epsilon$, proving that the sequence $\left\{a_{n}\right\}_{n=1}^{\infty}$ converges to $a_{0}$.

REMARK. Using the techniques in the remark following Lemma 1 , it can be shown that the function $f_{0}$ in Theorem 3 is a $\rho_{0}$-contraction with $\rho_{0}$-Lipschitz constant $\beta$.

REMARK. In the proof of Theorem 1 we showed that all but finitely many of the functions $f_{n}$ mapped the compact set $K\left(a_{0}, \varepsilon\right)$ into itself. We could have concluded (without the assumption that each $f_{n}$ had a fixed point) from Edelstein's Theorem 1 [1] that all the functions $f_{n}$ mapping $K\left(a_{0}, \varepsilon\right)$ into itself had fixed points. Furthermore, this procedure would prove that these fixed points converge to $a_{0}$.

3. Theorems for multi-valued mappings. Let $(X, \rho)$ be a metric space. By $2^{x}[C B(X)]$ we mean the space of all compact [closed and bounded] nonempty subsets of $X$ metrized by $H$, the Hausdorff metric induced by $\rho[2$, p. 131]. A function $F: X \rightarrow C B(X)$ is said to be a multi-valued $\rho$-contraction [ $\rho$-contractive] mapping if and only if there exists $\lambda<1$ such that $H(F(x), F(y)) \leqq \lambda \rho(x, y)$ for all $x$, $y \in X[H(F(x), F(y))<\rho(x, y)$ for all $x, y \in X$ with $x \neq y]$. A point $x \in X$ is said to be a fixed point for a function $F: X \rightarrow C B(X)$ if and only if $x \in F(x)$ (see [5] for further discussion).

Let $F$ be a continuous function from $X$ into $2^{x}$. If $A$ is in $2^{x}$, then $\cup\{F(a) \mid a \in A\}$ is also in $2^{X}\left[3\right.$, p. 168]. The function $\hat{F}: 2^{X} \rightarrow 2^{X}$ defined by $\hat{F}(A)=\cup\{F(a) \mid a \in A\}$ for each $A \in 2^{X}$ is called the function induced by $F$. (A function similarly defined on $C B(X)$ would not necessarily have values in $C B(X)$. Occasionally, when this more generally defined induced function has all its values in $C B(X)$, we will use it and denote it by $\hat{F}$.) It is easy to see that the continuity of $F$ implies the continuity of $\hat{F}$. If $F$ is a multi-valued $\rho$-contraction 
or $\rho$-contractive mapping, then $\hat{F}$ is a $\rho$-contraction [5] or (respectively, on $2^{X}$ ) a $\rho$-contractive mapping.

The next theorem is an extension of Theorem 1 in [1] and is closely related to Theorem 5 in [5]. Since the existence of fixed points is hypothesized in each of the theorems in $\$ 2$, it is not necessary to include the next theorem in order to generalize the results of §2 to set-valued mappings. However, it is included to show that restrictions similar to those imposed on single-valued contractive mappings guarantee that compact nonempty set-valued contractive mappings have fixed points.

Theorem 4. Let $(X, \rho)$ be a metric space and let $F: X \rightarrow 2^{X}$ be a multi-valued $\rho$-contractive mapping. If there exists $A \in 2^{X}$ such that some subsequence of the sequence $\left\{\hat{F}^{n}(A)\right\}_{n=1}^{\infty}$ of iterates of $\hat{F}$ at $A$ converges to a member of $2^{X}$, then $F$ has a fixed point.

Proof. Let $F: X \rightarrow 2^{X}$ be a multi-valued $\rho$-contractive mapping and let $A \in 2^{X}$ such that a subsequence $\left\{\hat{F}^{n i}(A)\right\}_{i=1}^{\infty}$ of $\left\{\hat{F}^{n}(A)\right\}_{n=1}^{\infty}$ converges to a set $B \in 2^{X}$. Now, since $\hat{F}$ is a $\rho$-contractive mapping (see comments above), we may apply Theorem 1 of [1] and obtain that $B$ is a fixed point of $\hat{F}$, i.e., $\hat{F}(B)=B$. Define a real-valued continuous function $g$ on $B$ by $g(x)=\inf \{\rho(x, y) \mid y \in F(x)\}$ for each $x \in B$. Since $B$ is compact, $g$ assumes its minimum $r$ at some point $b \in B$. Suppose $r>0$. Since $F(b)$ is compact, there is a point $z \in F(b)$ such that $g(b)=\rho(b, z)$. Because $g(b)=r>0, b \neq z$; also, since $z \in F(b), g(z) \leqq H(F(b), F(z))$. It follows that

$$
g(z) \leqq H(F(b), F(z))<\rho(b, z)=g(b) \text {, i.e., } g(z)<g(b) .
$$

However, since $\hat{F}(B)=B, z \in B$ and this contradicts the minimality of $g$ at $b$. Hence, $r=0$. It now follows that $b \in F(b)$, which proves the theorem.

REMARK. Let $F$ and $A$ satisfy the hypotheses of Theorem 4 and let $\left\{\hat{F}^{n_{i}}(A)\right\}_{i=1}^{\infty}$ be a convergent subsequence of $\left\{\hat{F}^{n}(A)\right\}_{n=1}^{\infty}$ such that $\lim _{i \rightarrow \infty} \hat{F}^{n_{i}}(A)=B \in 2^{X}$. Then

(1) $\left\{\hat{F}^{n}(A)\right\}_{n=1}^{\infty}$ converges to $B$ and

(2) there exists a point $p \in X$ such that $\left\{\hat{F}^{n}(\{p\})_{n=1}^{\infty}\right.$ converges to $B$.

The proof of (1) is the same as the argument in Remark 3.2 of [1]. To prove (2), choose $p \in B$. Then, since $2^{B}$ is compact and $\widehat{F}^{n}(\{p\}) \in 2^{B}$ for each $n=1,2, \cdots$, the sequence $\left\{\hat{F}^{n}(\{p\})\right\}_{n=1}^{\infty}$ has a convergent subsequence which must, since it converges to the unique 
fixed point of $\hat{F}[1]$, converge to $B$. By (1), with $\{p\}$ playing the role of $A$, it now follows that $\left\{\hat{F}^{n}(\{p\})\right\}_{n=1}^{\infty}$ converges to $B$.

REMARK. Let $\hat{F}$ and $B$ be as in the proof of Theorem 4, i.e., $\hat{F}(B)=B$. We proved that there is a fixed point of $F$ in $B$. Later we shall use the fact that every fixed point of $F$ is in $B$ and we now verify this. Let $x_{0}$ be a fixed point of $F$ and suppose $x_{0} \notin B$. Then $\inf \left\{\rho\left(x_{0}, y\right) \mid y \in B\right\}=\eta>0$ and, since $B$ is compact, there is $y_{0} \in B$ such that $\rho\left(x_{0}, y_{0}\right)=\eta$. Since $H\left(F\left(x_{0}\right), F\left(y_{0}\right)\right)<\rho\left(x_{0}, y_{0}\right)=\eta$ and $x_{0} \in F\left(x_{0}\right)$, there is $z_{0} \in F\left(y_{0}\right)$ such that $\rho\left(x_{0}, z_{0}\right)<\eta$. But, since $\hat{F}(B)=$ $B$ and $y_{0} \in B, F\left(y_{0}\right) \subset B$ which implies that $z_{0} \in B$. This contradicts the definition of $\eta$.

Since a multi-valued contradiction mapping on a complete space into $C B(X)$ has a fixed point [5], one might conjecture that Theorem 4 could be extended to multi-valued contractive mappings into $C B(X)$ (assuming $\hat{F}$ maps into $C B(X)$ ). This is not possible in general, as is seen in the following

EXAMPLE. Let $X=\left\{x_{n} \mid n=0, \pm 1, \pm 2, \cdots\right\} \cup\{y\}$ be a countable set of distinct points and define a metric $\rho$ for $X$ by the conditions

(1) $\rho\left(x_{n}, x_{n}\right)=\rho(y, y)=0$ for all $n=0, \pm 1, \pm 2, \cdots$;

(2) $\rho\left(x_{n}, y\right)=\rho\left(y, x_{n}\right)=10$ for all $n=0, \pm 1, \pm 2, \cdots$;

and (3) $\rho\left(x_{n}, x_{m}\right)=\gamma_{n}+\gamma_{m}$ for $x_{n}, x_{m} \in X$ with $x_{n} \neq x_{m}$, where

$$
\gamma_{k}=\frac{1}{4}+\frac{1}{2^{k}} \quad \text { if } \quad k>0 \text { and } \quad \gamma_{k}=2+\frac{1}{k-1} \quad \text { if } \quad k \leqq 0 .
$$

It is easy to verify that $\rho$ is a metric. Define $F: X \rightarrow C B(X)$ by letting $F(y)=X-\{y\}$ and $F\left(x_{n}\right)=x_{n+1}$ for each $x_{n} \in X$. It is easy to see that $F$ is a multi-valued $\rho$-contractive mapping and that $\hat{F}$ maps $C B(X)$ into $C B(X)$. Since $\hat{F}^{n}(\{y\})=X-\{y\}$ for each $n=$ $1,2, \cdots$, it is obvious that the sequence $\left\{\hat{F}^{n}(\{y\})\right\}_{n=1}^{\infty}$ converges (to $X-\{y\})$. However, $F$ has no fixed point. It is interesting to note that, though $\hat{F}$ maps $C B(X)$ into $C B(X), \hat{F}$ is not a contractive mapping. Also note that $(X, \rho)$ is complete.

We now present the types of modifications necessary to obtain generalizations of the results in $\S 2$ to multi-valued mappings. For the remainder of this section $H_{n}$ will denote the Hausdorff metric for $2^{X}$ induced by $\rho_{n}$ for $n=0,1,2, \cdots$.

It is well-known that equivalent metrics for $X$ may not induce equivalent Hausdorff metrics for $C B(X)$ [2, p. 131]. However, equivalent metrics for $X$ do induce equivalent metrics for $2^{x}$. We need the following lemma. 
LEMma 2. If $\rho_{1}$ and $\rho_{2}$ are equivalent metrics for $X$, then $H_{1}$ and $H_{2}$ are equivalent metrics for $2^{X}$.

Proof. Let $\left\{A_{i}\right\}_{i=1}^{\infty}$ be a sequence in $2^{X}$ such that $\left\{A_{i}\right\}_{i=1}^{\infty}$ converges, with respect to $H_{1}$, to a set $A \in 2^{X}$. It follows that $B=\left(\bigcup_{i=1}^{\infty} A_{i}\right) \cup A$ is a compact subset of $X[3, \mathrm{p} .168]$. Hence, $\left.\rho_{1}\right|_{B}$ is uniformly equivalent to $\left.\rho_{2}\right|_{B}$. Therefore, since $\left.H_{n}\right|_{2^{B}}$ is the Hausdorff metric induced by $\left.\rho_{n}\right|_{B}$ for each $n=1$ or 2 , it now follows that $\left.H_{1}\right|_{{ }_{2} B}$ is equivalent to $\left.H_{2}\right|_{2^{B}}$. Thus, the sequence $\left\{A_{i}\right\}_{i=1}^{\infty}$ converges to $A$ with respect to $H_{2}$. By symmetry we obtain the desired result (cf. 4).

Now we show how to generalize Theorem 1 of $\S 2$.

Let $\left(X, \rho_{0}\right)$ be a locally compact metric space and let $\left\{\rho_{n}\right\}_{n=1}^{\infty}$ be a sequence of metrics for $X$ converging uniformly on $X$ to $\rho_{0}$ such that each $\rho_{n}$ is equivalent to $\rho_{0}$. For each $n=0,1,2, \cdots$, let $F_{n}: X \rightarrow 2^{X}$ be a multi-valued $\rho_{n}$-contractive mapping with the property that there is a set $A_{n} \in 2^{X}$ such that some subsequence of $\left\{\hat{F}_{n}^{k}\left(A_{n}\right)\right\}_{k=1}^{\infty}$ converges to a member of $2^{X}$ or, equivalently, that $\hat{F}_{n}$ has a fixed point $B_{n} \in 2^{X}$ (that such an hypothesis is necessary is discussed in the remark below). Let $a_{n}$ be a fixed point of $F_{n}$ for each $n=1,2, \cdots$ (actually, $a_{n}$ exists for each $n$ by Theorem 4 above).

Suppose the sequence $\left\{F_{n}\right\}_{n=1}^{\infty}$ converges pointwise on $X$ to $F_{0}$. By Lemma 2, $H_{n}$ is equivalent to $H_{0}$ for each $n=1,2, \cdots$. Routine computations show that the sequence $\left\{H_{n}\right\}_{n=1}^{\infty}$ converges uniformly on $2^{X}$ to $H_{0}$. A slight modification of the proof of Lemma 1 shows that $\left\{F_{n}\right\}_{n=1}^{\infty}$ converges $\left(H_{0}-\right)$ uniformly on compact subsets of $X$ to $F_{0}$. This implies that $\left\{\hat{F}_{n}\right\}_{n=1}^{\infty}$ converges pointwise on $2^{X}$ to $\hat{F}_{0}$. Since $\left(2^{X}, H_{0}\right)$ is locally compact, we can now apply Theorem 1 to the sequence $\left\{B_{n}\right\}_{n=1}^{\infty}$ and conclude that $\left\{B_{n}\right\}_{n=1}^{\infty}$ converges to $B_{0}$. Since $a_{n} \in B_{n}$ for each $n=1,2, \cdots$ (see the 2nd remark following Theorem 4 ), $\left\{a_{n}\right\}_{n=1}^{\infty}$ is a sequence of points in the compact set $\cup\left\{B_{n} \mid n=0,1,2, \cdots\right\}$. Hence, $\left\{a_{n}\right\}_{n=1}^{\infty}$ has a convergent subsequence which, by an easy modification of Lemma 3 of [5], must converge to a fixed point of $F_{0}$ (note that not every point in $B_{0}$ is necessarily a fixed point of $F_{0}$ ).

REMARK. The restriction above that $\hat{F}_{n}$ have a fixed point in $2^{x}$ was necessary (even in the case where $X$ is complete; compare with Theorem 9 [5]). To see this let

$$
X=\left\{x_{i} \mid x_{i}=i+1+\frac{i}{i+1} \text { for each } i=0,1,2, \cdots\right\}
$$

with absolute value distance. Define $F: X \rightarrow 2^{X}$ by

$$
F\left(x_{i}\right)=\left\{x_{0}, x_{1}, \cdots, x_{i}+1\right\} \text { for each } i=0,1,2, \cdots
$$


It is easy to verify that $F$ is a multi-valued contractive mapping and that $\hat{F}: 2^{X} \rightarrow 2^{X}$ has no fixed point. Each point of $X$ is a fixed point of $F$. If we let

$$
F_{n}=F \quad \text { and } \quad a_{n}=n+1+\frac{n}{n+1}
$$

for each $n=0,1,2, \cdots$, then we see that $\left\{F_{n}\right\}_{n=1}^{\infty}$ converges to $F_{0}$ but $\left\{a_{n}\right\}_{n=1}^{\infty}$ has no convergent subsequence.

The modifications of other theorems in $\S 2$ are carried out in an analogous fashion.

4. Added in proof. This result is contained in [3] as Theorem 3.3.

\section{BIBLIOGRAPHY}

1. M. Edelstein, On fixed and periodic points under contractive mappings, J. London Math. Soc. 37 (1962), 74-79.

2. J. L. Kelley, General topology, D. Van Nostrand Co., Inc., Princeton, New Jersey, 1959.

3. E. Michael, Topologies on spaces of subsets, Trans. Amer. Math. Soc. 71 (1951), $152-182$.

4. S. B. Nadler, Jr., Sequences of contractions and fixed points, Pacific J. Math. 27 (1968), 579-585.

5. — Multi-valued contraction mappings, Pacific J. Math. 30 (1969), 475-488.

Received January 22, 1969, and in revised form April 23, 1969.

LOUISIANA State UNIVERsity

Baton ROUge, LOUISIANA 



\title{
PACIFIC JOURNAL OF MATHEMATICS
}

\author{
EDITORS
}

\author{
H. ROYDEN \\ Stanford University \\ Stanford, California \\ RICHARD PIERCE \\ University of Washington \\ Seattle, Washington 98105
}

\author{
J. DUGUNDJI \\ Department of Mathematics \\ University of Southern California \\ Los Angeles, California 90007 \\ BASIL GORDON \\ University of California \\ Los Angeles, California 90024
}

\section{ASSOCIATE EDITORS}

E. F. BECKENBACH
B. H. NeumanN

F. WOLF
K. YoshidA

\section{SUPPORTING INSTITUTIONS}

\author{
UNIVERSITY OF BRITISH COLUMBIA \\ CALIFORNIA INSTITUTE OF TECHNOLOGY \\ UNIVERSITY OF CALIFORNIA \\ MONTANA STATE UNIVERSITY \\ UNIVERSITY OF NEVADA \\ NEW MEXICO STATE UNIVERSITY \\ OREGON STATE UNIVERSITY \\ UNIVERSITY OF OREGON \\ OSAKA UNIVERSITY \\ UNIVERSITY OF SOUTHERN CALIFORNIA
}

\author{
STANFORD UNIVERSITY \\ UNIVERSITY OF TOKYO \\ UNIVERSITY OF UTAH \\ WASHINGTON STATE UNIVERSITY \\ UNIVERSITY OF WASHINGTON

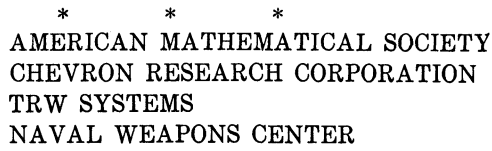

The Supporting Institutions listed above contribute to the cost of publication of this Journal, but they are not owners or publishers and have no responsibility for its content or policies.

Mathematical papers intended for publication in the Pacific Journal of Mathematics should be in typed form or offset-reproduced, double spaced with large margins. Underline Greek letters in red, German in green, and script in blue. The first paragraph or two must be capable of being used separately as a synopsis of the entire paper. It should not contain references to the bibliography. Manuscripts, in duplicate if possible, may be sent to any one of the four editors. Please classify according to the scheme of Math. Rev. 36, 1539-1546. All other communications to the editors should be addressed to the managing editor, Richard Arens, University of California, Los Angeles, California, 90024.

50 reprints are provided free for each article; additional copies may be obtained at cost in multiples of 50 .

The Pacific Journal of Mathematics is published monthly. Effective with Volume 16 the price per volume (3 numbers) is $\$ 8.00$; single issues, $\$ 3.00$. Special price for current issues to individual faculty members of supporting institutions and to individual members of the American Mathematical Society: $\$ 4.00$ per volume; single issues $\$ 1.50$. Back numbers are available.

Subscriptions, orders for back numbers, and changes of address should be sent to Pacific Journal of Mathematics, 103 Highland Boulevard, Berkeley, California, 94708.

PUBLISHED BY PACIFIC JOURNAL OF MATHEMATICS, A NON-PROFIT CORPORATION

Printed at Kokusai Bunken Insatsusha (International Academic Printing Co., Ltd.), 7-17, Fujimi 2-chome, Chiyoda-ku, Tokyo, Japan. 


\section{Pacific Journal of Mathematics}

\section{Vol. 31, No. $3 \quad$ BadMonth, 1969}

George E. Andrews, On a calculus of partition functions .................. 555

Silvio Aurora, A representation theorem for certain connected rings ............ 563

Lawrence Wasson Baggett, A note on groups with finite dual spaces ............. 569

Steven Barry Bank, On majorants for solutions of algebraic differential equations in regions of the complex plane ............................... 573

Klaus R. Bichteler, Locally compact topologies on a group and the corresponding continuous irreducible representations ......................... 583

Mario Borelli, Affine complements of divisors ....................... 595

Carlos Jorge Do Rego Borges, A study of absolute extensor spaces ............. 609

Bruce Langworthy Chalmers, Subspace kernels and minimum problems in Hilbert

spaces with kernel function ...................................... 619

John Dauns, Representation of L-groups and F-rings................. 629

Spencer Ernest Dickson and Kent Ralph Fuller, Algebras for which every

indecomposable right module is invariant in its injective envelope ...........

Robert Fraser and Sam Bernard Nadler, Jr., Sequences of contractive maps and fixed

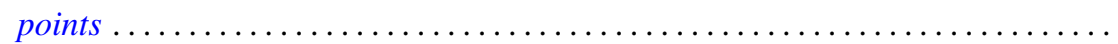

Judith Lee Gersting, A rate of growth criterion for universality of regressive

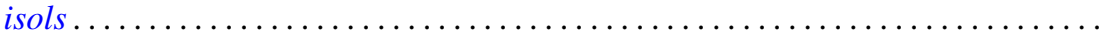

Robert Fred Gordon, Rings in which minimal left ideals are projective ............

Fred Gross, Entire functions of several variables with algebraic derivatives at certain algebraic points

W. Charles (Wilbur) Holland Jr. and Stephen H. McCleary, Wreath products of ordered permutation groups .........................

W. J. Kim, The Schwarzian derivative and multivalence .................. 717

Robert Hamor La Grange, Jr., On $(\mathrm{m}-\mathrm{n})$ products of Boolean algebras ......... 725

Charles D. Masiello, The average of a gauge ........................ 733

Stephen H. McCleary, The closed prime subgroups of certain ordered permutation

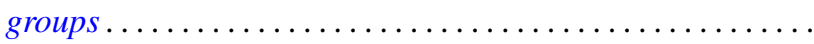

Richard Roy Miller, Gleason parts and Choquet boundary points in convolution measure algebras ...............................

Harold L. Peterson, Jr., On dyadic subspaces ........................ 773

Derek J. S. Robinson, Groups which are minimal with respect to normality being intransitive........................................... 777

Ralph Edwin Showalter, Partial differential equations of Sobolev-Galpern type . . . 787

David Slepian, The content of some extreme simplexes ................... 795

Joseph L. Taylor, Noncommutative convolution measure algebras ............. 809

B. S. Yadav, Contractions of functions and their Fourier series ............... 827

Lindsay Nathan Childs and Frank Rimi DeMeyer, Correction to automorphisms of separable algebras" ....................... 833

Moses Glasner and Richard Emanuel Katz, Correction to: "Function-theoretic degeneracy criteria for Riemannian manifolds".............

Satish Shirali, Correction to: "On the Jordan structure of complex Banach

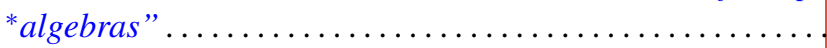

